\title{
BMJ Open Academic versus non-academic neurosurgeons in China: a national cross-sectional study on workload, burnout and engagement
}

Jinli Yu, ${ }^{1,2}$ Jiming Gao, ${ }^{3}$ Junyan Chen, ${ }^{4}$ Yirui Sun ${ }^{5}$

To cite: Yu J, Gao J, Chen J, et al. Academic versus nonacademic neurosurgeons in China: a national cross-sectional study on workload, burnout and engagement. BMJ Open 2019:9:e028309. doi:10.1136/ bmjopen-2018-028309

- Prepublication history for this paper is available online. To view these files, please visit the journal online (http://dx.doi org/10.1136/bmjopen-2018028309).

Received 01 December 2018 Revised 18 August 2019 Accepted 23 September 2019

Check for updates

(c) Author(s) (or their employer(s)) 2019. Re-use permitted under CC BY-NC. No commercial re-use. See rights and permissions. Published by BMJ.

${ }^{1}$ Department of International Education and Cooperation, Huashan Hospital, Fudan University, Shanghai, China ${ }^{2}$ Continuing Medical Education, Harvard Medical School, Boston, Massachusetts, United States ${ }^{3}$ Department of Medical Education, Huashan Hospital, Fudan University, Shanghai,

China

${ }^{4}$ The Artificial Intelligence and Big Data Business Division,

East China Institute of

Telecommunications, Shanghai, China

${ }^{5}$ Department of Neurosurgery, Huashan Hospital, Fudan University, Shanghai, China

Correspondence to Dr Yirui Sun; yirui.sun@live.cn

\section{ABSTRACT}

Objectives Chinese neurosurgery has made great progress during the past decades; yet, little is known about the working status of neurosurgeons. This study aimed to evaluate the difference between academic and nonacademic neurosurgeons, focusing on their professional burnout, job satisfaction and work engagement.

Design Cross-sectional nationwide survey.

Study setting The survey was conducted in China between 2017 and 2018.

Participants A total number of 823 academic neurosurgeons and 379 non-academic neurosurgeons participated in this study.

Outcome measures Professional burnout, job satisfaction and work engagement were assessed using the Maslach Burnout Inventory, the Job Descriptive Index and the Utrecht Work Engagement Scale, respectively.

Results The majority of respondents were male (92.93\%), less than 45 years old (85.27\%) and married (79.53\%). Chinese neurosurgeons worked $63.91 \pm 11.04$ hours per week, and approximately $45 \%$ experienced burnout. Compared with non-academic respondents, academic neurosurgeons had longer working hours $(p<0.01)$, higher income $(p<0.01)$ and were less willing to get married $(p<0.01)$. In addition, they showed a lower degree of burnout $(p<0.01)$, a higher level of job satisfaction $(p<0.01)$ and were more enthusiastic at work $(p=0.015)$. Multivariate regression analyses indicated that divorced (OR $7.02,95 \% \mathrm{Cl} 2.37$ to 15.08) and workplace violence (OR $1.52,95 \% \mathrm{Cl} 1.18$ to 2.24) were associated with burnout for both academic and non-academic respondents. Long working hours ( $\geq 71$ hours per week) and low annual income ( $<100000 \mathrm{RMB})$ were risk factors for burnout among academic neurosurgeons. For nonacademic neurosurgical surgeons (age 36-45 years), working as attending doctors, serving in public hospitals and having the first house-living child were all closely related to the incidence of burnout.

Conclusion Chinese neurosurgeons are under significant stress particularly for the non-academic neurosurgeons. Offering better opportunities for training, promotion, higher income and safer working environments could be solutions to relieve burnout and improve career satisfaction and engagement.

Trial registration number ChiCTR1800014762. This article is not linked to a clinical trial.

\section{Strengths and limitations of this study}

This is the first national cross-sectional survey to assess the working status of Chinese neurosurgeons.

- Worldwide common questionnaires including Maslach Burnout Inventory-Human Services Survey, Index of Job Satisfaction and Utrecht Work Engagement Scale were applied in the survey. The results would facilitate a comparison with previous and future studies.

- Subgroup analyses were performed to illustrate burnout levels among junior and senior neurosurgeons.

- Despite a large number (1202) of respondents, the study covered approximately $16 \%$ of Chinese neurosurgeons. Selection bias may exist.

- A comparison with other clinical specialists would also be interesting for future investigations.

\section{INTRODUCTION}

Chinese neurosurgery has a relatively short history. The first formal record of neurosurgical procedure could be traced back to 1950 , when the first craniotomy operation was performed by Dr Kefei Shan and Yuquan Shi in Shanghai. ${ }^{1}$ At that time, Chinese neurosurgical facilities started with only a few pioneer surgeons and limited beds. ${ }^{12} \mathrm{~A}$ remarkable milestone in the development of Chinese neurosurgery was the foundation of the Chinese Neurosurgical Society (CNS) in $1986 .{ }^{34}$ To date, modern neurosurgical clinic centres have been established in many major cities, with some performing over 8000 sophisticated operations annually. ${ }^{1}$ According to the World Federation of Neurosurgical Societies (WFNS) and the $\mathrm{CNS},{ }^{5}$ China has approximately 11000 registered neurosurgeons, which is the largest group of neurosurgeons in the world. In addition, Chinese neurosurgery has made remarkable progress in academic research. It is indicated that China has contributed approximately $4.2 \%$ of published 
neurosurgical research in the world (ranked fifth in the world behind USA, Japan, Germany and UK) and emerged as the only country among the top five with substantial growth of neurosurgical research productivity $(121.9 \% \pm 9.98 \%$ per year $){ }^{6}$

Despite the remarkable achievement, to our knowledge, there have been few published studies revealing the working status of Chinese neurosurgeons. The training programme and career path of a neurosurgeon in China are different from that in the Western world. In China, the healthcare system involves hospitals of three levels. General practitioners usually work in level I hospitals, also known as community health centres. Level I hospitals provide primary healthcare and are not equipped with neurosurgical facilities. The level II hospitals, also known as regional medical centres, recruit specialists including neurosurgeons. Routine neurosurgical operations can be performed in these hospitals. The level III (tertiary) hospitals are usually university teaching hospitals and national medical centres. Neurosurgeons working in tertiary hospitals are required to not only take care of complex cases (usually transferred from regional hospitals) but also conduct clinical/basic research, teaching and tutoring. Therefore, the neurosurgical surgeons working in tertiary hospitals are usually considered academic neurosurgeons and those working in regional hospitals as the non-academic. For young doctors who are interested in neurosurgery, after graduation from medical school, they are recruited to work either in a regional or a tertiary hospital and start their training as neurosurgeon residents. The updated (since 2003) training programme requires a neurosurgeon resident to complete two stages (5-7 years in total) standardised training before they can apply for senior positions such as attending and then consulting neurosurgeons. Although young trainees may apply to work for a different hospital (eg, from a non-academic to academic centre), the number of successful applicants is very limited. A brief introduction of the Chinese neurosurgery system and training system can be found elsewhere. ${ }^{4}$

Due to the inherent difference of the academic and non-academic medical specialists in China, a natural belief holds that the academic neurosurgeons are under significant stress as a result of additional responsibilities. However, during our previous study to assess the working status of Chinese physicians from various specialties, subgroup analyses suggested that surgeons working in regional hospitals were actually more stressed (submitted and under review). Nevertheless, in-depth investigations could not be performed due to limited case numbers. Here, we reported the results on a national survey on Chinese neurosurgeons. The focus of this study is to reveal the working status, as well as the difference between academic and non-academic of neurosurgeons. Detailed methods and results are described below.
MATERIALS AND METHODS

\section{Study design and questionnaires}

From June 2017 to September 2018, a national online survey was conducted in mainland China using both smartphone apps and website visiting under the support of the East Institution of China Academy of Information and Communications Technology. This study was part of a two-phase national survey on the working and living status of Chinese physicians, which was approved and registered with the Chinese Clinical Trial Registry. The phase I investigation was conducted between June 2017 and February 2018, recruiting 1167 physicians of various specialties. This part focused on the comparison between specialties (submitted elsewhere and under review). The phase II investigation was conducted between March and September 2018, in which the working and living status of each specialty is further investigated. Answers from resident/attending/senior neurosurgeons in both phase I and II investigations were analysed in this study. Potential respondents were invited to complete the online questionnaires via mailing lists of the Shanghai Medical Doctor Association, the national continuing education platform 'Neurosurgery News' and the professional networks of the authors. Neurosurgeons were also invited during national or local conferences via two-dimensional barcodes scanning. An introduction of the research purpose and methods was provided at the beginning of the online survey. Informed consent was received electronically from each respondent. All answers were collected anonymously. To avoid repeated participation, each IP address was restricted to fill out the questionnaire once.

The questionnaire consisted of 147 closed-end questions, organised in sections including demographic and practice characteristics, professional burnout, job satisfaction and work engagement. Most questions were derived from the well-established and standard scales (see below). A few questions were derived from previous studies ${ }^{7-9}$ or were developed by the authors. Details for each section are described as follows.

\section{Demographic and practice characteristics}

Respondents were asked to provide gender, marital and family status, job titles, nature of employers, weekly working hours, annual income, experience of workplace violence and whether a respondent would encourage his/ her kid(s) to become a doctor. Neurosurgical respondents working in tertiary hospitals were considered academic neurosurgeons, and those from regional hospitals were considered as non-academic neurosurgeons.

\section{Burnout}

Professional burnout was measured by the 22-item Maslach Burnout Inventory-Human Services Survey (MBI-HSS). In previous studies on professional burnout, heterogeneities have been recognised regarding the different tools and questionnaire versions. However, the original 22-item version of MBI-HSS is still one of the 
most commonly used tools to measure burnout. ${ }^{10}$ The 22 items coving three dimensions: Emotional Exhaustion (EE, nine items), Depersonalisation (DP, five items) and Personal Accomplishments (PA, eight items). Answers to each question were designed according to the frequency of a respondent's encountering situations on a 7-point scale, from 'never' ( 0 points) to 'daily' (six points). MBI scores of each dimension were further graded as high, intermediate or low (low $\mathrm{EE} \leq 18$; high $\mathrm{EE} \geq 27$; low DP $\leq 5$, high DP $\geq 10$; low $\mathrm{PA} \leq 33$; high $\mathrm{PA} \geq 40$ ). ${ }^{11}$ A respondent would be considered burnt out if he/she had high scores in the EE or DP assessment. ${ }^{11-13}$ The internal consistency of the questionnaire was presented as Cronbach's $\alpha$ values for each section $(0.91,0.90$ and 0.85 , respectively).

\section{Job satisfaction}

The respondents' job satisfaction was assessed by the Index of Job Satisfaction (JDI). The JDI questionnaire contained questions on five independent dimensions, namely Work Itself (22 items), Pay (9 items), Promotion (7 items), Co-workers (11 items) and Supervision (14 items). ${ }^{14}{ }^{15}$ Each item was scored Yes $=3$, ? $=1$ and $\mathrm{No}=0$, with negatively worded items being reverse-coded. A JDI score for each respondent was calculated as the sum of all his/her answers, with the scores of the Promotion and Pay sections being multiplied by 2. The Cronbach's $\alpha$ values of the five JDI subscales were $0.89,0.94,0.88,0.90$ and 0.87 , respectively.

\section{Work engagement}

Work engagement was measured using the 17-item Utrecht Work Engagement Scale (UWES). The UWES had three subscales: Vigour (six items), Dedication (five items) and Absorption (six items). All items were rated on a 7-point Likert scale (0-6). The sum of all items was used as a UWES score. ${ }^{16-18}$ The internal consistency for the UWES questionnaire was presented as a Cronbach's $\alpha$ value of 0.85 .

\section{Data analysis}

Data analysis was performed using SPSS V.18 (SPSS). Quantitative data were presented as means \pm SD. Shapiro-Wilk $\mathrm{W}$ test and $\mathrm{F}$ test were performed for normality and homogeneity. Independent samples t-test, Wilcoxon rank-sum test and one-way analysis of variance were used for the quantitative data of independent groups. Chi-square and Fisher exact tests were used for nominal variables. Statistical significance was considered with a two-tailed $\mathrm{p}$ value $<0.05$.

\section{Patient and public involvement}

No patients were involved in this study. The public has not been involved in the development of the research or in the study design. The study results will be disseminated to respondents via newsletters and publications.
RESULTS

\section{Demographic and practice characteristics of respondents}

A total number of 1202 neurosurgeons completed the survey. Considering the fact that approximately two-thirds of 11000 registered neurosurgeons in China have received proper training and are active, ${ }^{19}$ the pool of responding neurosurgeons in this study may represent approximately $16 \%$ of Chinese neurosurgeons.

The demographic and practice characteristics of responding neurosurgeons were summarised in table 1 . Their mean age was $34.32 \pm 7.21$ years, with a male to female ratio of 13.14:1. Among the respondents, 956 (79.53\%) were married and $50(4.16 \%)$ were divorced. Approximately three-quarters of neurosurgeons had home-living children, and $23.87 \%$ ( $30.02 \%$ of the married) had more than one child. The majority $(91.93 \%)$ of responding neurosurgeons worked in public hospitals. They worked an average of $63.91 \pm 11.04$ hours a week, with an annual income of $11.13 \pm 4.85 \wedge 10^{4}$ RMB (approximately 16 $000 \pm 6990$ USD). Interns, residents, attending doctors and senior/chief neurosurgeons constituted 3.00\%, 27.95\%, $42.35 \%$ and $26.71 \%$ of all respondents, respectively. Over one-third $(37.94 \%)$ of surveyed neurosurgeons claimed that they had experienced or witnessed workplace violence against doctors or other medical workers in the last 5 years. Only $6.6 \%$ of respondents would encourage their offspring to become a doctor.

Among the 1202 respondents, there were 823 (68.47\%) academic and 379 (31.53\%) non-academic neurosurgeons. The two groups had no statistical difference in terms of gender, age, marital status and job titles. However, a larger proportion of academic neurosurgeons were single compared with the non-academic $(19.93 \%$ vs $8.44 \%, \mathrm{p}<0.01)$, and the former preferred to have fewer children after marriage (table 1). While the majority $(91.93 \%)$ of academic neurosurgeons were working in public hospitals, nearly $18 \%$ of non-academic neurosurgeons chose to work in private medical facilities $(\mathrm{p}<0.01$, table 1). Both academic and non-academic neurosurgeons spent approximately 60 hours per week on clinical work $(56.17 \pm 9.12$ vs $61.42 \pm 7.92$ hours, $\mathrm{p}<0.01)$. For the academic neurosurgeons, they required additional $8.21 \pm 4.64$ hours per week on teaching and research such as university lectures, laboratory work, clinical trials, and paper writing, making their average working hours significantly longer than that of the non-academic $(p<0.01$, table 1). Accordingly, the average annual income of the academic neurosurgeons was statistically higher than that of their non-academic colleagues $\left(11.37 \pm 4.29 \wedge 10^{4} \mathrm{RMB}\right.$, $16300 \pm 6100$ USD vs $10.02 \pm 5.21 \wedge 10^{4} \mathrm{RMB}, 14300 \pm 7500$ USD, $\mathrm{p}<0.01)$. The gap in income was also reflected by the difference in proportions of high-income individuals (table 1). Some other notable difference included that the non-academic neurosurgeons had a higher risk of experiencing or witnessing workplace violence $(44.06 \%$ vs $35.12 \%, \mathrm{p}<0.01)$. Additionally, it is worth noting that the academic neurosurgeons were less likely to encourage their child (ren) to become a doctor $(\mathrm{p}<0.01)$ (table 1$)$. 
Table 1 Demographic and practice characteristics of respondents

All neurosurgeons $(n=1202) \quad$ Academic $(n=823)$

n $\quad \% \quad \%$

Non-academic $(n=379)$

\begin{tabular}{|c|c|c|c|c|c|c|c|}
\hline & & & \multicolumn{2}{|c|}{ INon-academic (n=s/y) } & \multirow[b]{2}{*}{ P value* } \\
\hline & $\mathrm{n}$ & $\%$ & $\mathrm{n}$ & $\%$ & n & $\%$ & \\
\hline \multicolumn{8}{|l|}{ Gender } \\
\hline Male & 1117 & 92.93 & 757 & 91.98 & 360 & 94.99 & 0.069 \\
\hline Female & 85 & 7.07 & 66 & 8.02 & 19 & 5.01 & 0.069 \\
\hline \multicolumn{8}{|l|}{ Age (years) } \\
\hline$\leq 35$ & 586 & 48.75 & 406 & 49.33 & 180 & 47.49 & 0.58 \\
\hline $36-45$ & 439 & 36.52 & 307 & 37.30 & 132 & 34.83 & 0.41 \\
\hline $46-55$ & 158 & 13.14 & 99 & 12.03 & 59 & 15.57 & 0.092 \\
\hline$\geq 56$ & 19 & 1.58 & 11 & 1.34 & 8 & 2.11 & 0.47 \\
\hline \multicolumn{8}{|l|}{ Marital status } \\
\hline Married & 956 & 79.53 & 630 & 76.55 & 326 & 86.02 & $<0.01$ \\
\hline Unmarried & 196 & 16.31 & 164 & 19.93 & 32 & 8.44 & $<0.01$ \\
\hline Divorced & 50 & 4.16 & 29 & 3.52 & 21 & 5.54 & 0.11 \\
\hline \multicolumn{8}{|c|}{ Number of kids (married only) } \\
\hline 0 & 80 & 8.37 & 74 & 11.75 & 6 & 1.84 & $<0.01$ \\
\hline 1 & 589 & 61.61 & 392 & 62.22 & 197 & 60.43 & 0.59 \\
\hline$\geq 2$ & 287 & 30.02 & 164 & 26.03 & 123 & 37.73 & $<0.01$ \\
\hline \multicolumn{8}{|c|}{ Nature of current employer } \\
\hline Public & 1105 & 91.93 & 794 & 96.48 & 311 & 82.06 & $<0.01$ \\
\hline Private & 97 & 8.07 & 29 & 3.52 & 68 & 17.94 & $<0.01$ \\
\hline \multicolumn{8}{|c|}{ Professional status } \\
\hline Intern & 36 & 3.00 & 25 & 3.04 & 11 & 2.90 & 0.99 \\
\hline Resident & 336 & 27.95 & 241 & 29.28 & 95 & 25.07 & 0.13 \\
\hline $\begin{array}{l}\text { Attending } \\
\text { doctor }\end{array}$ & 509 & 42.35 & 342 & 41.56 & 167 & 44.06 & 0.41 \\
\hline Senior/chief & 321 & 26.71 & 215 & 26.12 & 106 & 27.97 & 0.50 \\
\hline \multicolumn{8}{|c|}{ Working hours per week (hours, mean \pm SD) } \\
\hline Total & $63.91 \pm 11.04$ & & $64.39 \pm 9.63$ & - & $61.92 \pm 8.34$ & & $<0.01$ \\
\hline Clinic & $58.19 \pm 10.34$ & & $56.17 \pm 9.12$ & & $61.42 \pm 7.92$ & & $<0.01$ \\
\hline Research & $5.72 \pm 3.67$ & & $8.21 \pm 4.64$ & & $0.53 \pm 0.36$ & & $<0.01$ \\
\hline \multicolumn{8}{|c|}{ Annual income (10 000RMB) } \\
\hline$<6$ & 202 & 16.81 & 121 & 14.70 & 81 & 21.37 & $<0.01$ \\
\hline $6-10$ & 384 & 31.95 & 231 & 28.07 & 153 & 40.37 & $<0.01$ \\
\hline $11-15$ & 366 & 30.45 & 264 & 32.08 & 102 & 26.91 & 0.071 \\
\hline $16-20$ & 172 & 14.31 & 140 & 17.01 & 32 & 8.44 & $<0.01$ \\
\hline$\geq 20$ & 78 & 6.49 & 67 & 8.14 & 11 & 2.90 & $<0.01$ \\
\hline \multicolumn{8}{|c|}{ Experience or witness of workplace violence in the last 5 years } \\
\hline Yes & 456 & 37.94 & 289 & 35.12 & 167 & 44.06 & $<0.01$ \\
\hline \multicolumn{8}{|c|}{ Encouraging child to become a doctor } \\
\hline Yes & 80 & 6.66 & 55 & 6.68 & 25 & 6.60 & 0.99 \\
\hline No & 876 & 72.88 & 573 & 69.62 & 303 & 79.95 & $<0.01$ \\
\hline Not sure & 246 & 20.47 & 195 & 23.69 & 51 & 13.46 & $<0.01$ \\
\hline
\end{tabular}

Bold values indicate $p$ values less than 0.05 .

"-" indicates not applicable.

*The $p$ values indicate the difference between the academic and the non-academic neurosurgeons. A p value less than 0.05 is considered as statistical significance. 
Table 2 Burnout measured by MBI-HSS

\begin{tabular}{|c|c|c|c|c|c|c|c|}
\hline \multirow[b]{2}{*}{ Burnout subscales } & \multicolumn{2}{|c|}{ All neurosurgeons $(n=1202)$} & \multicolumn{2}{|c|}{ Academic $(n=823)$} & \multicolumn{2}{|c|}{ Non-academic $(n=379)$} & \multirow[b]{2}{*}{ P value* } \\
\hline & $\mathbf{n}$ & $\%$ & $\mathbf{n}$ & $\%$ & $\mathbf{n}$ & $\%$ & \\
\hline \multicolumn{8}{|l|}{ Emotional Exhaustion } \\
\hline Intermediate & 573 & 47.67 & 414 & 50.30 & 159 & 41.95 & $<0.01$ \\
\hline High & 434 & 36.11 & 273 & 33.17 & 161 & 42.48 & $<0.01$ \\
\hline Low & 543 & 45.17 & 394 & 47.87 & 149 & 39.31 & $<0.01$ \\
\hline Intermediate & 303 & 25.21 & 253 & 30.74 & 50 & 13.19 & $<0.01$ \\
\hline High & 356 & 29.62 & 176 & 21.39 & 180 & 47.49 & $<0.01$ \\
\hline \multicolumn{8}{|c|}{ Personal Accomplishment } \\
\hline Low & 533 & 44.34 & 363 & 44.11 & 170 & 44.85 & 0.81 \\
\hline
\end{tabular}

Bold values indicate $p$ values less than 0.05 .

*The $p$ values indicate the difference between the academic and the non-academic neurosurgeons. A $p$ value less than 0.05 is considered as statistical significance.

MBI-HSS, Maslach Burnout Inventory-Human Services Survey .

\section{Career burnout}

Career burnout was assessed by the 22-item MBI-HSS questionnaire and summarised in table 2. Overall, $44.51 \%$ of responding neurosurgeons were burnout. There were $36.11 \%$ of respondents showing high levels of EE, $29.62 \%$ with high DP and $12.26 \%$ with a low sense of PA (table 2). Although the academic neurosurgeons had longer weekly working hours and more workload, the incidence of burnout was significantly lower among the academic neurosurgeons $(37.91 \%$ vs $58.84 \%, \mathrm{p}<0.01)$. In fact, the academic neurosurgeons scored better in all three assessed dimensions $(\mathrm{p}<0.01, \mathrm{p}<0.01$ and $\mathrm{p}<0.01$, respectively, table 2 ). Additional analysis was performed to illustrate the difference in burnout rate among neurosurgeons with different job titles. Table 3 indicates that the non-academic neurosurgeons at all levels had higher burnout rates than their academic colleagues. In addition, for both academic and non-academic respondents, the senior/chief neurosurgeons were less likely being burnout than intern/resident or attending neurosurgeons (table 3).

\section{Job satisfaction}

Job satisfaction was measured by JDI and the five subscales (table 4). The mean JDI score for all surveyed neurosurgeons was $102.60 \pm 36.63$. Previous studies have been conducted in other countries using JDI to measure job satisfaction. For example, Rahnavard et $a t^{20}$ and Lee $e t$ $a l^{21}$ reported a mean JDI between 175 and 190 of mental health professionals and nursing staff. A JDI of 102 of this study is significantly lower than the scores reported by other authors, indicating a lower level of job satisfaction. Interestingly, the academic neurosurgeons showed significantly higher scores (being more satisfied) when they were asked to comment on Work Itself, Promotion and Supervision $(\mathrm{p}<0.01, \mathrm{p}<0.01$ and $\mathrm{p}<0.01$, respectively,

Table 3 Burnout measured by MBI-HSS among neurosurgeons with different job titles

\begin{tabular}{|c|c|c|c|c|c|c|c|}
\hline & \multicolumn{2}{|c|}{ All neurosurgeons } & \multicolumn{2}{|c|}{ Academic } & \multicolumn{2}{|c|}{ Non-academic } & \multirow[b]{2}{*}{ P value* } \\
\hline & $n$ & Burnout, n (\%) & $n$ & Burnout, n (\%) & $\mathbf{n}$ & Burnout, n (\%) & \\
\hline Intern/resident & 372 & $162(43.54)$ & 266 & $108(40.60)$ & 106 & $63(59.43)$ & $<0.01$ \\
\hline Senior/chief & 321 & $120(37.38) \dagger \ddagger$ & 215 & $59(27.44) \dagger \ddagger$ & 106 & 45 (42.45)†‡ & $<0.01$ \\
\hline
\end{tabular}

Bold values indicate $p$ values less than 0.05

${ }^{*}$ The $p$ values indicate the difference between the academic and the non-academic neurosurgeons. A $p$ value less than 0.05 is considered as statistical significance.

†There were statistic differences in the burnout rates between the group of intern/resident and the senior/chief neurosurgeons. $\ddagger$ There were statistic differences in the burnout rate between the group of attending doctor and the senior/chief neurosurgeons. MBI-HSS, Maslach Burnout Inventory-Human Services Survey. 
Table 4 Job satisfaction measured by JDI

\begin{tabular}{|c|c|c|c|c|c|c|c|}
\hline \multirow[b]{2}{*}{ JDI subscales } & \multicolumn{2}{|c|}{ All neurosurgeons $(n=1202)$} & \multicolumn{2}{|c|}{ Academic $(n=823)$} & \multicolumn{2}{|c|}{ Non-academic $(n=379)$} & \multirow[b]{2}{*}{ P value $^{x}$} \\
\hline & Mean & SD & Mean & SD & Mean & SD & \\
\hline JDI score & 102.60 & 36.63 & 107.04 & 36.48 & 92.95 & 35.12 & $<0.01$ \\
\hline Pay & 7.44 & 4.22 & 7.60 & 4.09 & 7.11 & 4.84 & 0.059 \\
\hline Promotion & 6.73 & 4.55 & 7.09 & 4.29 & 5.92 & 4.99 & $<0.01$ \\
\hline Coworker & 24.53 & 10.60 & 25.32 & 10.76 & 24.83 & 10.07 & 0.45 \\
\hline
\end{tabular}

Bold values indicate $p$ values less than 0.05 .

${ }^{*}$ The $p$ values indicate the difference between the academic and the non-academic neurosurgeons. A $p$ value less than 0.05 is considered as statistical significance.

JDI, Index of Job Satisfaction.

table 4). There was no statistical difference in the comments on Pay and Coworker $(\mathrm{p}=0.059$ and $\mathrm{p}=0.45$, respectively, table 3 ).

\section{Work engagement}

The UWES scores indicated the difference in work engagement between the academic and the non-academic neurosurgeons (table 5). Overall, the academic neurosurgeons scored higher (being more enthusiastic for work) than their non-academic colleagues $(p=0.015)$. For UWES subscales, academic neurosurgeons were more dedicated to work $(\mathrm{p}<0.01)$. Yet, the academic and non-academic neurosurgeons showed no difference in the Vigour and Absorption assessment ( $\mathrm{p}=0.057, \mathrm{p}=0.059$, respectively, table 5).

\section{Multivariate analysis}

Multivariate regression analysis indicated that, for both academic and non-academic neurosurgeons, being divorced, having one (or the first) home-living child, working as attending doctors, prolonged working hours ( $\geq 71$ hours per week), low annual income ( $<100000 \mathrm{RMB}$, $\sim 14400$ USD) and workplace violence were significantly related to professional burnout (table 6). For non-academic neurosurgeons, working in public hospitals was an independent risk factor for burnout (OR 5.37, 95\% CI 2.969 to $9.67, \mathrm{p}<0.01)$. In addition, surgeons' age, number of home-living children and job titles were associated with burnout among non-academic neurosurgeons but not the academic respondents (table 6). Subgroup analysis also indicated that academic neurosurgeons may have a relatively lower expectation of income. While the annual income between 110000 and 150000 RMB (14400-21 600 USD) was related to professional burnout among the academic neurosurgeons (OR $0.63,95 \%$ CI 0.46 to 0.86 , $\mathrm{p}<0.01$ ), a similar association was only observed when the annual income exceeded $160000 \mathrm{RMB}$ (23000 USD) among the non-academic respondents (OR 0.29, 95\% CI 0.15 to $0.58, \mathrm{p}<0.01$, table 6 ).

\section{DISCUSSION}

There is no doubt that Chinese neurosurgery has made a remarkable improvement in the past decades. ${ }^{346}$ On the stage of today's neurosurgery, the voice of the Chinese can often be heard. In spite of the fact that Chinese neurosurgery has shown progresses not only in the case numbers and operating techniques but also in the amount and quality of academic research, little attention has been paid to the working status of Chinese neurosurgical surgeons to date.

In this study, a national survey was conducted to address this issue. Our survey indicates that Chinese

Table 5 Job engagement measured by UWES

\begin{tabular}{|c|c|c|c|c|c|c|c|}
\hline \multirow[b]{2}{*}{ UWES subscales } & \multicolumn{2}{|c|}{ All neurosurgeons $(n=1202)$} & \multicolumn{2}{|c|}{ Academic $(n=823)$} & \multicolumn{2}{|c|}{ Non-academic $(n=379)$} & \multirow[b]{2}{*}{ P value* } \\
\hline & Mean & SD & Mean & SD & Mean & SD & \\
\hline UWES score & 61.27 & 26.21 & 62.52 & 25.53 & 58.55 & 27.49 & 0.015 \\
\hline Dedication & 18.03 & 8.83 & 18.57 & 8.48 & 16.86 & 9.46 & $<0.01$ \\
\hline Absorption & 21.20 & 9.75 & 21.57 & 9.55 & 20.41 & 10.13 & 0.057 \\
\hline
\end{tabular}

Bold values indicate $p$ values less than 0.05 .

${ }^{*} T$ The $p$ values indicate the difference between the academic and the non-academic neurosurgeons. A $p$ value less than 0.05 is considered as statistical significance.

UWES, Utrecht Work Engagement Scale. 
Table 6 Multivariate analysis on burnout

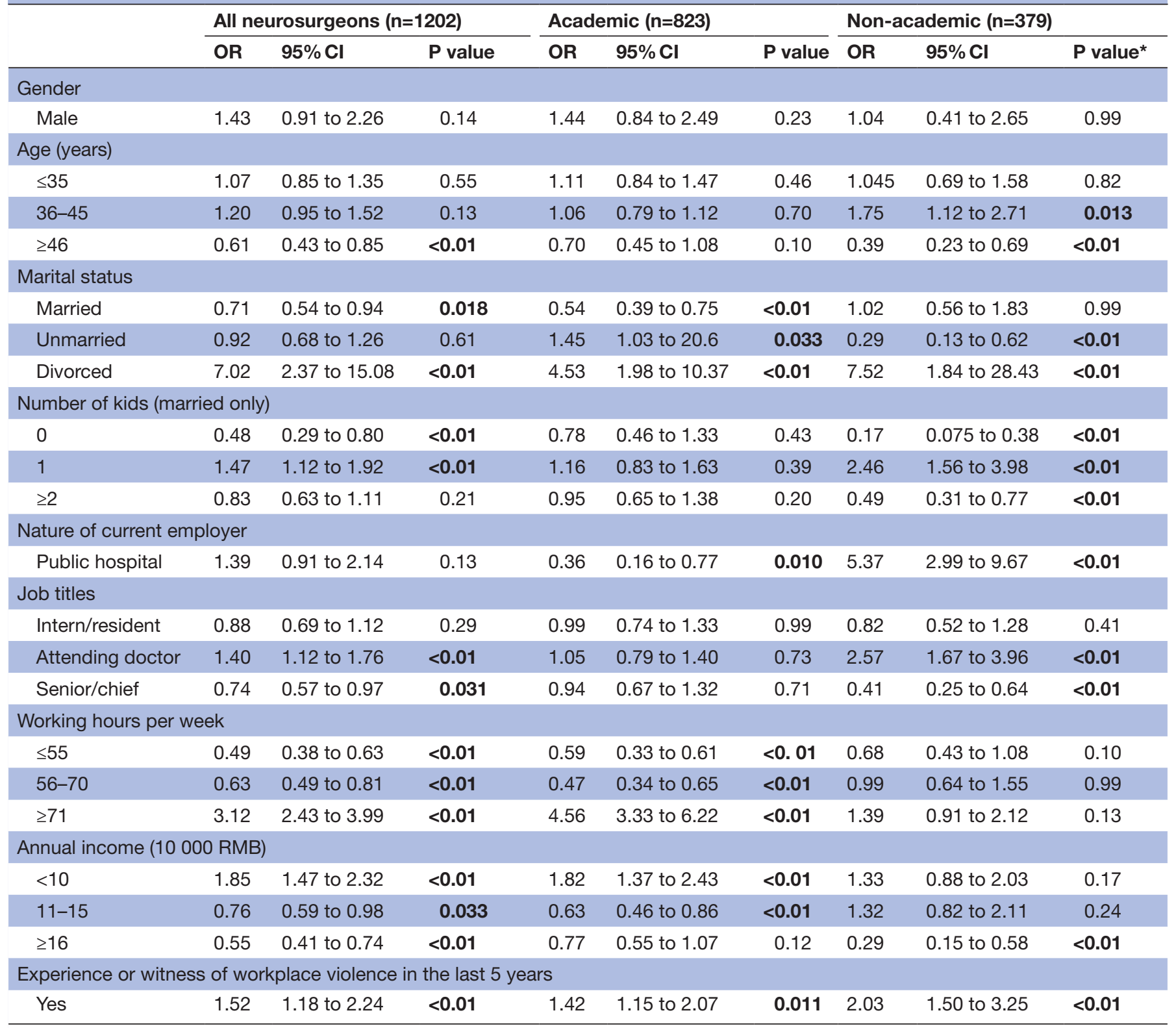

Bold values indicate $p$ values less than 0.05 .

${ }^{\star} \mathrm{A} p$ value less than 0.05 is considered as statistical significance.

neurosurgeons are under great pressure. Vast workload, prolonged working hours, high incidence of burnout and low job satisfaction have been noted among all levels of neurosurgeons. Professional burnout has been previously investigated among neurosurgeons in the USA (27\%$56.7 \%$ of neurosurgeons being burnout) ${ }^{11} 13$ and in Europe (one-quarter of neurosurgeons being burnout). ${ }^{22}$ A recent meta-analysis found that the global prevalence of burnout of residents was $51 \% .^{23}$ However, this study did not report the prevalence of burnout of neurosurgery residents. In this study, the burnout ratio of Chinese neurosurgeons was $44.51 \%$, which was similar to the results of the USA but significantly higher than that of Europe. An interesting finding is that, although the academic neurosurgeons have heavier workloads and longer working hours than the non-academic neurosurgeons, they are more satisfied with their jobs, more committed to the work and less likely to experience professional burnout. The reasons for the phenomena are complex, and yet, we speculate several possible explanations, discussed as follows.

First of all, the income gap may play an important role. Our survey indicated that one of the most apparent differences between Chinese academic and non-academic neurosurgeons is that the former had a higher annual income (table 1). It has been demonstrated in multiple industries that pay is one of the most important contributors for job satisfaction, work engagement and, consequently, professional burnout. ${ }^{13}$ 24-26 Currently, Chinese tertiary hospitals are attracting an increasing number of 
patients due to reputations and skilful physicians. Under the principle of performance appraisal, which has been widely accepted by Chinese healthcare facilities, academic neurosurgeons have good reasons to be paid better than those working in regional hospitals. However, it does not imply that neurosurgeons are individuals with high income. On the contrary, although neurosurgeons are paid approximately 100000 to 110000 RMB (14400-15 800 USD) annually, which is 1.11-1.22 times more than the average salary of Chinese urban employees (89 993 RMB, 13000 USD, data from the National Bureau of Statistics of China, http://data.stats.gov.cn/easyquery. htm?cn=C01), neurosurgeons are actually underpaid considering their prolonged training, long working hours (nearly 70 hours per week) and vast workload.

Second, academic neurosurgeons may have better career development. As employees of university hospitals and national medical centres, academic neurosurgeons have more opportunities to get funding support and build collaborations, which is crucial for research breakthroughs and development of personal career. According to the records of WFNS (www.wfns.org), American Association of Neurological Surgeons (AANS, www. aans.org) and European Association of Neurosurgical Societies (EANS, www.eans.org), the three major organisations each holding an international neurosurgical conference annually, the majority of Chinese speakers or poster authors of those meetings came from tertiary hospitals. In addition, the database from ClinicalTrails ( www.clinicaltrials.gov) and Chinese Clinical Trial Registry (ChiCTR, www.chictr.org.cn) indicates that the majority of multicentre projects are led or exclusively recruit partners from tertiary hospitals. The advantages in career development, especially the chance of getting support at a national level and the opportunities of setting international collaborations with world-leading research facilities, may provide academic neurosurgeons a sense of superiority and, consequently, have positive impacts on job satisfaction and engagement. ${ }^{27}$

Third, tertiary hospitals provide a safer work environment. During the last two decades, the deterioration of the doctor-patient relationship has become a major issue in the Chinese medical system. Chinese doctors have been threatened by a surge of workplace violence. In 2017, the Chinese Medical Doctor Association (CMDA) released the latest version of 'White paper on medical practice in China', showing that $66 \%$ of Chinese physicians were involved in doctor-patient conflicts (www.cmda.net/u/ cms/www/201807/06181247ffex.pdf). The increase of doctor-patient conflicts has a significant impact on physician burnout, mental health, job satisfaction and drop-out. ${ }^{928}$ In our survey, nearly $40 \%$ of neurosurgeons have encountered workplace violence in the last 5 years. Nevertheless, the incidence among academic neurosurgeons was significantly lower than that among non-academic neurosurgeons. One possible explanation is that university teaching hospitals and national medical centres provide better security service than regional hospitals do.
In addition, the public holds the view that surgeons in tertiary hospitals are more skilled and better equipped. It is believed that academic neurosurgeons represent the highest level in this country; hence, more respect and fewer conflicts are expected.

The gap of pay, career development and safety between academic and non-academic neurosurgeons have attracted an increasing number of young talents to work in tertiary hospitals. If the gap continues to exist or even widens further, an inevitable consequence is that patients would prefer to choose tertiary hospitals even if their disorders could be well treated in regional hospitals. This trend would lead to an imbalance in medical resources and affect the quality of medical care. In order to solve the problem, in 2016 the Chinese authority initiated a new standardisation training programme requiring all Chinese neurosurgeons, particularly those working in regional hospitals, to finish an extra 4 years of specialist training. The intention of this reform is to enable all Chinese neurosurgeons to receive standardised training and to narrow their gap in skills and knowledge. In the meanwhile, the research management agencies, such as the Nature Science Foundation of China and many local foundations, have also provided increasing support for projects from regional hospitals.

This study has a few limitations. First of all, selection bias may exist during the process of the survey. There are approximately 11000 registered neurosurgeons in China. ${ }^{5}$ This is the largest group of neurosurgical specialists in the world. Although the number of 1202 respondents was similar to the US study and significantly larger than studies in other countries, ${ }^{13} 22$ the results of this study may only represent $16 \%$ of all Chinese neurosurgeons. Individuals who suffer from significant burnout or low morale were less likely to complete a voluntary survey. In other words, the survey may have provided more optimistic data. Moreover, the questionnaires were distributed electronically via smart-phone APPs and web pages, which may recruit more young respondents than elder surgeons. Second, for easier understanding and analysis, we simply considered neurosurgeons working in tertiary hospitals as the academic and those in regional hospitals as the non-academic. However, researches in regional hospitals are actually not down to zero. The Chinese healthcare system requires every doctor to publish at least two papers as one of the premise conditions for promotion, regardless of the type of hospital. In major cities such as Beijing and Shanghai, the conditions for promotion are more demanding, requesting publications in high standard international journals. Therefore, neurosurgeons in regional hospitals also conduct clinical or basic researches, although these researches are usually limited and under the help of tertiary hospitals. However, under the aforementioned new policy, it is a fact that some non-academic neurosurgeons were devoted to research and have made remarkable achievements. Although their number is limited, these 'non-academic' neurosurgeons could stay as potential confounders in this anonymous 
survey. Finally, further studies are required to illustrate the difference in job satisfaction and work engagement among neurosurgeons of different titles. A comparison with other clinical specialists would also be interesting for future investigations.

\section{CONCLUSION}

This study reveals the working status of Chinese neurosurgeons. It also illustrates the difference between the academic and the non-academic neurosurgeons in China. Our data suggest that Chinese neurosurgeons are under stress, particularly for those working in regional hospitals. We hope this study will promote reforms for better support and a safer working environment for Chinese neurosurgeons. We also hope this study may offer valuable information for medical students and young talents who would choose neurosurgery, a promising but challenging profession, as a career.

Fortunately, the Chinese authority recently has increasingly emphasised the legitimate rights and interests of medical workers. In addition, starting from 2018, it will be the August 19th of each year as the Chinese Physician's Day. All in all, having healthy and professionally satisfied physicians including neurosurgeons is the essential precondition for improved healthcare. The change may take a long time, but the future is promising.

Acknowledgements We thank Dr Fei Zou, Dr Jian Yu, Dr Jianping Song and Dr Jingjing Xia for supporting this study. We also thank Diane Bartram for proofreading and suggestions during the revision.

Contributors JY and YS drafted the manuscript and were involved in the interpretation of the data. JG and JC performed statistical analyses. JY, JC and YS played a major role in questionnaire development. All the authors read and approved the final manuscript.

Funding This work was supported by Shanghai Municipal Science and Technology Commission project (16411955300, 18441903300), Shanghai Municipal Commission of Health and Family Planning project (201840063, 201801075), The Major and Develop Project of Chinese Ministry of Science and Technology (2017ZX09304005), the Public Medical Artificial Intelligence Training Platform (XX-RGZN-01-17-4684) and Shanghai Minhang Nature Science Foundation project (2018MHZO07).

Competing interests None declared.

Patient consent for publication Not required.

Ethics approval The Ethics Review Committee of Huashan Hospital, Fudan University, approved the study design and the collection of the data through the questionnaire.

Provenance and peer review Not commissioned; externally peer reviewed.

Data availability statement All data relevant to the study are included in the article or uploaded as supplementary information.

Open access This is an open access article distributed in accordance with the Creative Commons Attribution Non Commercial (CC BY-NC 4.0) license, which permits others to distribute, remix, adapt, build upon this work non-commercially, and license their derivative works on different terms, provided the original work is properly cited, appropriate credit is given, any changes made indicated, and the use is non-commercial. See: http://creativecommons.org/licenses/by-nc/4.0/.

\section{REFERENCES}

1 Wang C, Mao Y, Zhu J-H, et al. The Department of neurosurgery at Shanghai HUASHAN Hospital. Neurosurgery 2008;62:947-53. discussion 52-3.

2 Chou SN. Perspectives in international neurosurgery: a glimpse of neurosurgery in China. Neurosurgery 1978;3:120-2.

3 Ausman $\mathrm{Jl}$. The rise of Chinese neurosurgery and neurosurgery in the developing world, and scientific colonialism. Surg Neurol 2007;67:323-5.

4 Zhao J-Z, Zhou L-F, Zhou D-B, et al. The status quo of neurosurgery in China. Neurosurgery 2008;62:516-21. discussion 20-1.

5 Societies WFoN. Global neurosurgical workforce MAP. Available from. Available: https://www.wfns.org/menu/61/global-neurosurgicalworkforce-map [Accessed cited 2018 September 27].

6 Hauptman JS, Chow DS, Martin NA, et al. Research productivity in neurosurgery: trends in globalization, scientific focus, and funding. $J$ Neurosurg 2011;115:1262-72.10.3171/2011.8.JNS11857

7 Wu D, Wang Y, Lam KF, et al. Health system reforms, violence against doctors and job satisfaction in the medical profession: a cross-sectional survey in Zhejiang Province, eastern China. BMJ Open 2014;4:e006431.

8 Tijdink JK, Vergouwen ACM, Smulders YM. Emotional exhaustion and burnout among medical professors; a nationwide survey. $B M C$ Med Educ 2014;14:183.

9 Wáng Y-XJ, Káplár Z, L YT. AME survey-003 A1-part 2: the motivation factors of medical doctors in China. Quant Imaging Med Surg 2015;5:917-24.

10 Rotenstein LS, Torre M, Ramos MA, et al. Prevalence of burnout among physicians: a systematic review. JAMA 2018;320:1131-50.

11 Klimo P, DeCuypere M, Ragel BT, et al. Career satisfaction and burnout among U.S. neurosurgeons: a feasibility and pilot study. World Neurosurg 2013;80:e59-68.

12 Shanafelt TD, Balch CM, Bechamps GJ, et al. Burnout and career satisfaction among American surgeons. Ann Surg 2009;250:463-71.

13 McAbee JH, Ragel BT, McCartney S, et al. Factors associated with career satisfaction and burnout among US neurosurgeons: results of a nationwide survey. $J$ Neurosurg 2015;123:161-73.

14 Hulin CL, Smith PC. A linear model of job satisfaction. Journal of Applied Psychology 1965;49:209-16.

15 Smith PC, Kendall LM, Hulin CL. The measurement of satisfaction in work and retirement. Chicago: Rand McNally, 1969.

16 Schaufeli WB, Salanova M, González-romá V, et al. The measurement of engagement and burnout: a two sample confirmatory factor analytic approach. J Happiness Stud 2002;3:71-92.

17 Schaufeli WB, Bakker AB, demands J. Job demands, job resources, and their relationship with burnout and engagement: a multi-sample study. J Organ Behav 2004;25:293-315.

18 Fong TC-tat, $\mathrm{Ng} \mathrm{S}$-man. Measuring engagement at work: validation of the Chinese version of the Utrecht work engagement scale. Int $J$ Behav Med 2012;19:391-7.

19 Zhang YQ, Xue C, Mao Y, et al. Current status and development of Chinese neurosurgeons]. Chinese Journal of Neurosurgery 2011;27:217-9.

20 Lee CD, del Carmen Montiel E. The correlation of mentoring and job satisfaction: a pilot study of mental health professionals. Community Ment Health J 2011;47:482-7.

21 Rahnavard F, Sadati AK, Hemmati S, et al. The impact of environmental and demographic factors on nursing job satisfaction. Electron Physician 2018;10:6712-7.

22 Pranckeviciene A, Tamasauskas A, Deltuva VP, et al. Professional burnout and its correlates in Lithuanian neurosurgeons. Acta Neurochir 2016;158:1437-45.

23 Low ZX, Yeo KA, Sharma VK, et al. Prevalence of burnout in medical and surgical residents: a meta-analysis. Int J Environ Res Public Health 2019;16:1479.

24 Judge TA, Piccolo RF, Podsakoff NP, et al. The relationship between pay and job satisfaction: a meta-analysis of the literature. $J$ Vocat Behav 2010;77:157-67.

25 Kulikowski K, Sedlak P. Can you buy work engagement? the relationship between pay, fringe benefits, financial bonuses and work engagement. Current Psychology 2017;22:1-11.

26 Stringer C, Didham J, Theivananthampillai P. Motivation, pay satisfaction, and job satisfaction of front-line employees. Qualitative Res Acc \& Man 2011;8:161-79.

27 de Oliveira Vasconcelos Filho P, de Souza MR, Elias PEM, Elias PEM, et al. Physicians' job satisfaction and motivation in a public academic hospital. Hum Resour Health 2016;14:75.

28 Wang $Y$, Fang M, Wang Y. How to decrease violence against doctors in China? Int J Cardiol 2016;211:66. 